\title{
INFÂNCIAS E DIREITOS: UMA DÉCADA DE PESQUISAS APRESENTADAS NA ANPED
}

\author{
Sílvia Cardoso Rocha ${ }^{1}$
}

\begin{abstract}
Resumo: Este trabalho é um recorte de uma pesquisa de Doutorado, em andamento, na Universidade Federal de Santa Catarina, UFSC, vinculada ao Programa de Pós-Graduação em Educação, na Linha de Pesquisa Ensino e Formação de Educadores, que tem por objetivo investigar a relação entre Educação e Justiça, a partir do Programa de Enfrentamento à Evasão Escolar (APOIA-SC). Nesse intuito a investigação delineia à temática das infâncias e a violação de seus direitos com enfoque na questão dos maus-tratos. Consideramos que, "as situações de maus-tratos são entendidas como todos os atos ou omissões na proteção da criança, que podem resultar em danos de caráter físico, emocional, intelectual ou social, cometidos pelos responsáveis pelo seu bem estar" (Benetti, 2002). Pesquisar os maus-tratos contra crianças requer posicionamento ético e político. A complexidade do conceito de maustratos não pode ser desconsiderada por estar diretamente relacionada às violências. A metodologia desta pesquisa de doutorado é de natureza qualitativa, integrada a uma abordagem etnográfica. Este texto fraciona um dos tópicos abordados na tese: o mapeamento dos trabalhos apresentados nas reuniões anuais da Associação Nacional de Pós-Graduação e Pesquisa em Educação (ANPED) durante a década que abrange os anos de 2005 a 2015 e que, configura parte do estado do conhecimento desta pesquisa.
\end{abstract}

Palavras-chave: Maus-Tratos. Educação. Justiça.

\section{INFANCIES AND RIGHTS: A DECADE OF RESEARCH PRESENTED AT THE ANPED}

Abstract: This work is a cross-section of a $\mathrm{PhD}$ research, in progress, at the Federal University of Santa Catarina, UFSC, linked to the Post-Graduation Program in Education, in the Line of Research Teaching and Training of Educators, whose objective is to investigate the relation between Education and Justice, based on the Program to Combat School Evasion (APOIA-SC).

To this end, the investigation delineates the theme of childhood and the violation of their rights with a focus on maltreatment. We consider that "situations of maltreatment are understood as all acts or omissions in the protection of the child, which can result in physical, emotional, intellectual or social damages committed by those responsible for their well-being" (Benetti, 2002). Tracing child abuse requires ethical and political stance. The complexity of the concept of

\footnotetext{
1 Doutoranda em Educação da UFSC; Pesquisadora do Núcleo de Estudos e Pesquisas sobre as Violências- NUVIC e do Grupo de Pesquisa Etnografia e Infância, ambos vinculados à UFSC.
} 


\section{Revista Ibero-Americana de Humanidades, Ciências e Educação \\ Produção e democratização do conhecimento na Ibero-América}

mistreatment can not be disregarded because it is directly related to violence. The methodology of this doctoral research is qualitative in nature, integrated to an ethnographic approach. This text breaks down one of the topics covered in the thesis: the mapping of the papers presented at the annual meetings of the National Association of Postgraduate and Research in Education (ANPED) during the decade that covers the years 2005 to 2015 and which, part of the state knowledge of this research.

Keywords: Mistreatment. Education. Justice.

O levantamento da produção acadêmica de artigos, teses e dissertações em bases de dados traz a possibilidade de situar o/a pesquisador/a no processo de elaboração de um problema de estudo, comparando as abordagens teóricometodológicas utilizadas e apontando aproximações, contrastes ou lacunas entre os resultados das pesquisas. No início das investigações deste trabalho surgiram algumas perguntas: como a questão da violação de direitos da infância vem sendo estudada no Brasil? Qual o enfoque dado pelas pesquisas em Educação à problemática dos maus-tratos? Importa aqui compreender a presença ou ausência dos conceitos que integram a temática "Infância e MausTratos" e em que medida tem sido objeto de estudo de pesquisadores?

Tendo em vista a amplitude dos estudos e pesquisas sobre o tema maustratos, assunto que transcende diversas áreas do conhecimento e especialmente encontrado nas áreas das Ciências Humanas², Sociais e Saúde e por estar diretamente ligado à questão da violência direcionei a busca para os assuntos que envolvem esta pesquisa/tese, como: Infância e Violação de Direitos; Infância e Poder; Infância e Evasão escolar. E iniciei esse rastreamento na base de dados da Associação Nacional de Pós-Graduação e Pesquisa em Educação (ANPED) a partir da 28aㅗ edição até a 37ª , entre 2005 - 2015. Entre os Grupos de Trabalhos (GT's), a busca foi realizada em três (03) Grupos de Trabalhos (GT's ):

- GT 06 - Educação Popular;

- GT 07 - Educação de crianças de 0 a 6 anos e

\footnotetext{
2 A Tabela de áreas de Conhecimento da CAPES aponta a Área de Ciências Humanas constituída pela Educação, Psicologia, Sociologia, Filosofia, Teologia, Ciência Política, Geografia, História, Arqueologia e Antropologia.
} 


\title{
Revista Ibero-Americana de Humanidades, Ciências e Educação \\ Produção e democratização do conhecimento na Ibero-América
}

- GT 08 - Formação de Professores.

A metodologia de pesquisa foi a leitura dos títulos e/ou assuntos dos trabalhos completos e dos pôsteres publicados em cada GT nesses 10 anos de Encontros Nacionais da ANPED. Considerando os limites do critério, em seguida da análise do título, ano de publicação e autoria Após a leitura dos trabalhos foi possível verificar que há por parte dos pesquisadores uma preocupação pela proteção dos direitos da criança, ainda que os termos "maus-tratos" e "violação de direitos" não estejam elencados nos títulos, os textos discursam sobre a preocupação com a "violência" e "poder" sempre relacionados ao cuidado com as crianças e a infância. Encontrei 03 trabalhos que apresentam no título a palavra violência e relacionavam-se com temas, como: educação, cultura, cuidado de si, políticas públicas, ética e infância. Dentre eles, o trabalho de Monteiro (2005) destaca a reflexão acerca dos movimentos de globalização e do neoliberalismo, sua imposição política educacional aos países mais pobres e suas ações institucionais. Vale realçar que,

\begin{abstract}
Entendendo que o problema da violência na sociedade contemporânea ultrapassa os limiares das condições socioeconômicas, bem como, os "muros" da própria escola, uma nova concepção de educação, é uma iniciativa que propõe a (re)construção de princípios, valores e recursos educacionais, fundamentados em uma Política Pedagógica de NãoViolência, que vise, por um lado, o entrelaçamento complexo da realidade vivida com sonhos e subjetividades, e por outro, o desenvolvimento da consciência de cidadania e dignidade humana, pautada em uma Cultura de Paz e de um "Saber com Sabor" (MONTEIRO, 2005, p. 19).
\end{abstract}

Outro destaque de Monteiro (2005), que poderá ajudar a pensar os processos de violência, está em $A$ Vida nas Fronteiras, termo cunhado por Homi Bhabha ${ }^{3}$. A Vida nas Fronteiras é a possibilidade de criação em outros

\footnotetext{
${ }^{3}$ Homi Bhabha é professor doutor "Anne F. Rothenberg" de Humanidades, diretor do Centro de Humanidades Mahindra, conselheiro sênior do presidente e reitor da Universidade Harvard, EUA. Seu trabalho seminal "O Local da Cultura" apresenta uma teoria sobre o hibridismo cultural. É membro do conselho do Relatório Mundial da UNESCO sobre Diversidade Cultural. Atua no conselho do Prêmio Literário Homem Asiático, na Comissão Indo-americana de Museus
} 


\section{Revista Ibero-Americana de Humanidades, Ciências e Educação \\ Produção e democratização do conhecimento na Ibero-América}

locais da cultura, nesses entre-lugares encontram-se os fluxos privilegiados de interações, trocas e negociações que possibilitam as intersubjetividades individuais e coletivas como anuncia Bhabha. É espaço de acolhimento do Outro, do diferente, do estranho. Essa concepção de fronteiras culturais tem fortes confluências com a de inter e transdisciplinaridade nas ciências. Como diz Monteiro (2005, p.11) "em outras palavras, o "trans" (além, outro) se construindo no "inter" (entre-lugar, fronteira) pela via do diálogo (linguagem, escuta sensível)".

Cabe salientar que as crianças que sofrem maus-tratos são "sobreviventes das fronteiras", sujeitos que precisam cotidianamente se reinventar e se reinscrever na vida. O texto sugeriu aos educadores e responsáveis pela proteção desta população (a infantil) repensar conceitos como, a cultura, a violência e valores na educação, na intenção de dar efetividade às políticas públicas de proteção a estes sobreviventes.

Sobre Infância e Violência destaco o trabalho publicado por Sousa e Lima (2005), cujo objetivo era abordar algumas dimensões que pautam as violências contra a infância, razão que levou as autoras a apresentarem as violências como a principal categoria de análise, associada às políticas de governo do corpo na infância e o cuidado de si. $\mathrm{O}$ trabalho organizou-se a partir do olhar sobre a pesquisa que realizaram no decorrer de 2003 e 2004, junto a uma Rede de Atendimento às crianças vítimas de violências, através de algumas das suas unidades integrantes, as quais tornaram possível 0 acesso às fontes documentais, o diálogo com os educadores $e$ as educadoras, o acompanhamento de visitas domiciliares, a participação nas reuniões organizadas pelos profissionais para estudo de casos de crianças vitimizadas por diferentes modos de maus-tratos, as entrevistas semi-estruturadas, a observação etnográfica do campo em foco, os encontros temáticos para reflexões e as intervenções nos cursos de formação organizados pelos setores.

Um dado relevante no trabalho de Sousa e Lima (2005) foi a organização de uma Base de Dados 2001/2002, a partir dos indicadores coletados, que se constituiu uma experiência piloto e teve por alvo ampliar as parcerias para 


\section{Revista Ibero-Americana de Humanidades, Ciências e Educação \\ Produção e democratização do conhecimento na Ibero-América}

conquistar maior alcance regional e contar com o apoio financeiro das agências de fomentos para construir, em médio prazo, uma Base Estadual de Indicadores sobre as violências contra a infância. A intenção era subsidiar a instalação de outras políticas públicas, capazes de proteger com maior eficácia a infância, bem como, compartilhar/contribuir com as organizações nacionais e latinoamericanas no enfrentamento das violências.

O trabalho de Sousa e Lima (2005) realizou a escolha metodológica por uma abordagem etnográfica, com um olhar qualitativo para construir uma compreensão sobre a temática violência e infância. Dando enfoque para concepções que norteiam as práticas de atendimento nestas unidades, entre os quais destacaram o discurso jurídico-normativo, o médico-patológico e 0 pedagógico- assistencialista que transversalizam ações institucionais de atendimento às crianças violentadas. Considerou ainda, os saberes que orientam as condutas dos familiares na autojustificação das violências e na vitimização das crianças. Uma constatação importante é apontada pelas pesquisadoras Sousa e Lima (2005, p. 10):

[...] a pesquisa mostrou como as políticas públicas de atendimento e proteção à infância não abarcam a demanda e não correspondem às necessidades regionais do estado e também do país. Do mesmo modo, o sistema judiciário, aprisionado pela anacrônica burocracia de suas estruturas, não consegue implementar uma política ágil e congruente com as circunstâncias desses tipos de violências, capaz de punir o agressor, promover sua reeducação social e, simultaneamente, proporcionar à vítima o cuidado necessário ao seu amparo e à restauração de sua integridade humana violentada. Essa negligência instituída reforça os contextos de vulnerabilidade infantil, facilita as ações dos agressores e reproduz, num ciclo vicioso e recorrente, as probabilidades de uma sociedade violenta onde o agredido se torna, na vida adulta, um agressor em potencial. Eis porque os discursos normativo-jurídico, médico- patológico e pedagógico-assistencialista carecem de uma transfiguração teórico-prática que Ihes permitam dialogar com as contraposições dos contextos com os quais lidam cotidianamente.

Sousa e Lima (2005) amparam suas reflexões na teoria da complexidade, sustentada por Edgar Morin, Humberto Maturana, Luis Carlos Restrepo, Pablo Navarro, Alex Galeno, Assmann. E autores como, Michel Maffesoli e Michel Foucault contribuíram para a formulação dos conceitos de violência e poder, o 


\section{Revista Ibero-Americana de Humanidades, Ciências e Educação \\ Produção e democratização do conhecimento na Ibero-América}

que foi ampliado pela compreensão político-filosófica de Hannah Arendt. No campo mais específico, autores como Maria Clara Lucchetti, Roberto dos Santos, Alba Zaluar, Sérgio Adorno, Walter Kohan, Guacira Lopes Louro, Dagmar Meyer, Malvina Dorneles, entre No campo mais específico, autores como Maria Clara Lucchetti, Roberto dos Santos, Alba Zaluar, Sérgio Adorno, Walter Kohan, Guacira Lopes Louro, Dagmar Meyer, Malvina Dorneles, entre outros, colaboraram para a problematização das relações onde as violências se fizeram presentes.

Tanto o trabalho de Sousa e Lima (2005) quanto o trabalho de Rateke (2005) tratam a questão do cuidado de si e procuram evidenciar as estratégias de problematização da ética, enquanto uma instância que oportuniza a relação e o desenvolvimento do sujeito consigo mesmo, e com os Outros. Essa perspectiva pretende demonstrar como na relação pedagógica a negação dos espaços de cuidado de si, configuram-se em relações abusivas, de controle e domínio, constituindo-se em relações que se fundam na violência. As dimensões empregadas caminham no sentido da valoração de uma convivência humana que compreende e reconhece o Outro em sua legitimidade (RATEKE, 2005; SOUSA e LIMA, 2005). As contribuições de Foucault sustentam teoricamente os dois trabalhos e, por tratar das tecnologias do eu e do cuidado de si também oportunizam pensar a ética, as formas de governabilidade e o poder.

Os trabalhos que não possuíam os descritores acima mencionados foram excluídos deste estado do conhecimento, com exceção de 07 produções que apresentaram no título a palavra "participação" relacionada à "criança", à "infância" e "direito", sendo 06 trabalhos completos: Glaudio (2015); Oliveira (2015); Nazário (2015); Tavares (2015); Muller (2015) e Sousa (2015) e 01 pôster: Nazário (2015). Justificada, assim, a seleção pela importância das discussões sobre as mudanças ocorridas em relação aos estudos relacionados à criança e a infância. Tais pesquisas consideraram a participação infantil como uma grande transformação ocorrida nos modos de relação estabelecidos entre adultos e crianças. Trazem um enfoque na discussão atual do campo teórico que concebe a criança como um ator social e a infância enquanto categoria 


\section{Revista Ibero-Americana de Humanidades, Ciências e Educação \\ Produção e democratização do conhecimento na Ibero-América}

geracional.

Vale destacar: as pesquisas que envolviam os descritores "Infância, participação e direitos", aqui mencionadas, apoiaram-se teoricamente nos Novos Estudos da Infância, especialmente na Sociologia da Infância e deram enfoque aos Direitos. Outro dado comum das pesquisas ${ }^{4}$ foi a escolha por metodologias de pesquisa qualitativa e de abordagem etnográfica considerada por esses autores, propícia a escuta das vozes das crianças. Tavares (2015) ressalta nas considerações finais da pesquisa que,

[...] cabe a problematização de até quando as crianças vão ser ignoradas em seus desejos e expectativas pela sociedade e pelas instituições. É urgente a necessidade de que as metodologias que estejam mais próximas às suas realidades e que haja pessoas disponíveis

Oliveira (2015, p. 16) ressaltou: "dar voz às crianças não é somente deixálas falar, mas é buscar maneiras de compreender as teorizações sobre o mundo social que as perspectivas das crianças podem nos fornecer", ressalva dada por todos os outros pesquisadores aqui mencionados. Além das pesquisas citadas, que trazem a temática da participação, infância e direito, destaco a pesquisa apresentada por Filho (2010) que investigou outras pesquisas que se dedicaram a observar, analisar e compreender jeitos de ser criança, tendo em vista traçar, mapear e examinar os procedimentos teórico-metodológicos utilizados, bem como as concepções de criança e infância que foram apresentados na ANPED, no período compreendido entre 1999 e 2009, especificamente no GT 07 Educação de Crianças de zero a seis anos. No levantamento foram identificados, no total, 193 trabalhos, dos quais foram selecionados 38 trabalhos referentes às pesquisas com crianças, os quais foram lidos integralmente. Isso permitiu fazer outro enquadramento, pois apenas 25 dos 38 trabalhos realmente referiam-se às pesquisas com crianças. No que diz respeito aos trabalhos sobre estudos

\footnotetext{
${ }^{4}$ Exceto a pesquisa de Sousa (2015) que foi um estudo de caso de natureza qualitativa. E a pesquisa de Saravali (2005) cujo referencial teórico está baseado nas pesquisas sobre construção do conhecimento social segundo o enfoque piagetiano, e caracterizou-se como um estudo de caso em que as entrevistas realizadas foram baseadas no método clínico- crítico piagetiano.para escutá-las verdadeiramente (p.17).
} 


\section{Revista Ibero-Americana de Humanidades, Ciências e Educação \\ Produção e democratização do conhecimento na Ibero-América}

teórico-metodológicos de pesquisas com crianças, identificou apenas quatro trabalhos nesses últimos dez anos de ANPED, dois deles são os realizados por pesquisadoras brasileiras na Universidade do Minho em Braga/Portugal.

Filho (2010) destaca que a Sociologia da Infância é apontada nas pesquisas selecionadas como forte aporte teórico influenciando a escolha metodológica sublinhando como base teórica em maior escala autores portugueses como Pinto (1997); Sarmento (2009); Tomás (2000); Ferreira (2002).

Sobre os mecanismos de regulação e controle encontrei algumas aproximações entre os trabalhos de Nazário (2015), Menezes (2007), Barbosa; Richter (2011). Os textos discursam sobre as medidas de proteção utilizadas para efetivar a abrigagem de crianças ou sua "educação" e, analisam como a ação de conselheiros e juízes, na maioria das vezes, tem deslocado o caráter protetivo da medida para o lugar da punição. Tais pesquisas refletem sobre como a irrupção do poder de interditar, exercido por conselheiros tutelares e juízes, tem marcado crianças, desviando suas trajetórias. Os discursos produzidos têm influenciado ações de deslocamento da criança do lugar familiar para o lugar institucional.

Com a leitura dos 15 trabalhos apresentados entre os anos de 2005 e 2015 na ANPED, considero que a visibilidade da criança como sujeito de direitos, alcançada na sociedade contemporânea caminha ao lado dos altos índices de violências contra esta população. Nesse contexto, tais pesquisas reivindicam uma análise profunda sobre a construção de modos outros de "educar" e sugerem começar por interrogar as perspectivas educacionais que surgem do encontro entre adulto e criança e a abertura para uma outra sensibilidade na tecitura dos laços de convivência transgeracionais.

Destaco aqui que, o estado do conhecimento acerca da temática da infância e maus-tratos, no recorte temporal de 10 anos (2005 - 2015) evidencia a escassez de trabalhos voltados para a temática e sua interface com a Escola e o Sistema de Justiça. Os protocolos de atendimento às crianças maltratadas não foram uma preocupação dos pesquisadores ao longo da década 


\section{Revista Ibero-Americana de Humanidades, Ciências e Educação \\ Produção e democratização do conhecimento na Ibero-América}

mencionada, pelo menos não na área da Educação propriamente dita.

\section{Referências}

BARBOSA, Maria Carmen Silveira. RICHTER, Sandra Regina Simonis. Direitos das crianças como Estratégia para pensar a educação das crianças pequenas. In: Anais da 34를. ANPED. Caxambu: MG. 2011.

BENETTI, Silvia Pereira da Cruz. Maus-tratos da criança: abordagem preventiva. In: HUTZ, Cláudio Simon et al. (Org.). Situações de risco e vulnerabilidade na infância e na adolescência: aspectos teóricos e estratégicos de intervenção. São PAULO: Casa do Psicólogo, 2002. p. 131-150.

FERREIRA, Manuela. Estudos da Infância, antropologia e etnografia: potencialidades, limites e possibilidades. Linhas Críticas. Brasília: DF, v. 20, n 41, p. 103-123, jan./abr. 2014.

FILHO, Altino José Martins. Jeitos de ser criança: balanço de uma década de pesquisas com crianças apresentadas na ANPED. In: Anais da 33a ANPED. Caxambu: MG. 2010.

GAUDENCIO FILHO, Pedro; BASTOS, Ana C. N; GOUVEIA, Alessandra B de $\mathrm{M}$. O discurso dos principais atores sociais com inserção no campo educativo de Rio Formoso- PE sobre a categoria qualidade da educação. Revista IberoAmericana de Humanidades, Ciências e Educação. Criciúma, v. 6.n.8, 2020. DOI: https://doi.org/10.29327/211653.6.8-1

GLÁUDIO, Eduarda Souza. Dimensão étnico-racial na educação infantil: um olhar sobre a perspectiva das crianças. In: Anais da $37^{a}$ ANPED. Florianópolis: SC. 2015.

MENEZES, Marilu Nörnberg. Interdição: como fazemos isso que fazemos com nossas crianças: o trabalho do poder sobre as vidas e o discurso que dele nasce. In: Anais da 30을. ANPED. Caxambu, MG. 2007.

MONTEIRO, Aloísio Jorge de Jesus. Sobreviventes das fronteiras: cultura, violência e educação. In:

Anais da 28a ANPED. Caxambu: MG. 2005.

MULLER, Juliana Costa. Jogos e brincadeiras com o uso das tecnologias móveis na educação

infantil: o que as crianças têm a nos dizer? In: Anais da 37 ${ }^{\text {a }}$ ANPED. Florianópolis: SC. 2015. 


\section{Revista Ibero-Americana de Humanidades, Ciências e Educação \\ Produção e democratização do conhecimento na Ibero-América}

NAZÁRIO, Roseli. Entre estar na casa e estar em casa: modos de ser criança

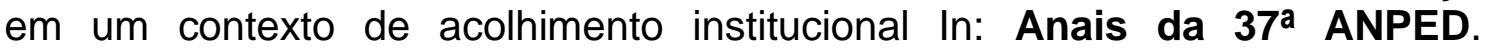
Florianópolis: SC. 2015.

NAZÁRIO, Roseli. Narrativas das experiências de criança pequenas no contexto de uma "Casa Lar" do município de Florianópolis - SC. In: Anais da 34ª ANPED. Natal: RN. 2011.

OLIVEIRA, Fabiana. A criança e sua relação com a sociedade: considerações sobre a participação infantil nos espaços públicos. In: Anais da 37ª ANPED. Florianópolis: SC. 2015.

PINTO, Manuel. A infância como construção social In: SARMENTO, Manuel Jacinto e PINTO, Manuel. As crianças, contextos e identidades. Braga, Portugal. Universidade do Minho. Centro de Estudos da Criança. Ed. Bezerra, 1997.

RATEKE, Deise. A Negação da Violência como Prática de Liberdade: o cuidado de si como estratégia e princípio de uma formação ética. In: Anais da 280 ANPED. Caxambu, MG. 2005.

SARAVALI, Eliane Giachetto. Trabalhando os direitos das crianças numa sala de

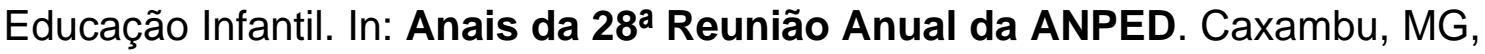
2005.

SARMENTO, Manuel. GOUVEA, Maria Cristina Soares de. Estudos da Infância: educação e práticas sociais. 2 ed. Petrópolis, RJ: Vozes, 2009.

SOUSA, Ana Maria Borges de; LIMA, Patrícia de Moraes. Violências e infância: as políticas de governo do corpo e o cuidado de si. In: Anais da 28ª Reunião Anual da Anped. Caxambu, MG, 2005.

SOUSA, José Edilmar de. Homem docência com crianças pequenas: o olhar das crianças de um centro de educação infantil. In: Anais da 37a ANPED. Florianópolis: SC. 2015.

TAVARES, Leandro Henrique de Jesus. Meu irmão tem 3 anos e não estuda porque ele é criancinha" - o que dizem as crianças sobre a educação infantil e 0 direito? In: Anais da 37ª ANPED. Florianópolis: SC.2015.

TOMÁS, Catarina. Há muitos mundos no mundo. Cosmopolitismo, participação e direitos da criança. Porto: Afrontamento. 2011. 